\title{
O que há (se de fato há algo) de errado com o capitalismo? Três vias de crítica do capitalismo*
}

\author{
What (if anything) is wrong with capitalism? Three paths of the \\ critique of capitalism
}

\author{
Rahel Jaeggi \\ rahel.jaeggi@staff.hu-berlin.de \\ (Humboldt Universität zu Berlin, Berlin, Alemanha)
}

\begin{abstract}
Resumo: Partindo da questão, com base em quais fundamentos o capitalismo pode ser hoje criticado, o texto categoriza os argumentos utilizados na crítica do capitalismo em três vias argumentativas (funcional, moral, ética) e as analisa em suas linhas de raciocínio. Além disso, examinaremos se seus pontos críticos realmente tematizam características específicas de um sistema econômico e social capitalista. Dessa forma, são expostos os pontos fortes e fracos de cada modelo de argumentação. Por fim, o artigo oferece um panorama de como uma possível combinação das diferentes vias da crítica poderia resolver os déficits identificados.
\end{abstract}

Palavras-chave: capitalismo; crítica funcionalista; crítica moral; crítica ética; crítica de formas de vida.

\begin{abstract}
Starting from the question of how capitalism can be criticized today, the text categorizes arguments brought forward against capitalism into three lines of reasoning (functional, moral, ethical) and analyzes their argumentative approaches. Furthermore, they are examined as to whether their points of critique discuss specific characteristics of a capitalist economic and social order. Thus, strengths and weaknesses of the different patterns of reasoning are exposed. Last, the paper offers an outlook on how the identified deficits could be resolved by combining the different approaches of critique.
\end{abstract}

Keywords: capitalism; functional critique; moral critique; ethical critique; critique of life forms.

DOI: http://dx.doi.org/10.11606/issn.2318-9800.v20i2p13-36

\section{Introdução:}

\section{A Conjuntura da Crítica do Capitalismo}

A crítica do capitalismo tem conjuntura. Marcada pelo estado de ânimo atual, essa crítica pode ser difusa, por vezes insuficientemente complexa e, em alguns aspectos, até estranhamente inflacionária. Há, contudo, boas razões para sua

\footnotetext{
*Artigo originalmente publicado sob o título "Was (wenn überhaupt etwas) ist falsch am Kapitalismus? 3 Wege der Kapitalismuskritik", Working Paper 01/2013 der DFG-Kolleg-Forscher/innengruppe Postwachstumsgesellschaften, Jena 2013.
} 
conjuntura ou, em todo caso, um motivo compreensível.

Mas qual é, de fato, o problema com o capitalismo? Ele é errado, ${ }^{1}$ injusto, irracional ou ruim? Ele é mau ou estúpido - ou simplesmente não funciona? Perguntando de outro modo, com base em quais fundamentos o capitalismo pode ser criticado?

Para responder a essa pergunta, eu não forneço nesse artigo novas informações, nem posso oferecer um diagnóstico econômico objetivamente novo da situação atual da economia mundial ou qualquer proposta construtiva para acabar com a crise. Em vez disso, gostaria de fazer o seguinte: vou analisar, com um propósito metodológico, três vias de crítica do capitalismo e então investigar como elas procedem e quais possibilidades para uma crítica do capitalismo, enquanto forma específica de organização econômica e social, estão vinculadas a elas. (Acima de tudo, portanto, me ocupo da questão metodológica: quais figuras de argumentação estão aqui em jogo e o quão promissoras elas são).

A questão “O que há (se de fato há algo) de errado com o capitalismo?" não possui assim um propósito cínico. Com ela, não quero deixar em aberto se atualmente há de fato algo de problemático no sistema econômico global e na constituição de nossas sociedades. Me parece muito menos evidente, no entanto, quais dos vários males desse mundo remontam de modo específico ao capitalismo e se há realmente, como perguntou Philippe Van Parijs, algo de intrinsecamente errado com o capitalismo. ${ }^{2}$

Será que há algo que não seja uma mera consequência fortuita de algumas manifestações individuais do capitalismo, mas que surja de forma sistemática em conexão com ele (e apenas com ele) - e que seja além disso (justificavelmente) problemático? O objeto de nossa crítica - uma vez que ela quer ser uma crítica do capitalismo - não pode, com efeito, ser algo que surge em todas as formações sociais concebíveis; nem pode a crítica, uma vez que quer ser uma crítica do capitalismo, dizer respeito a algo que surja junto com ele apenas por acaso. Dito de outro modo: se deve haver algo de errado ou de problemático nos sistemas sociais a serem considerados, o capitalismo é realmente o culpado por isso? Ou é talvez a modernidade ou mesmo a conditio humana em geral?

Essa questão não me parece trivial, já que atualmente muitas reflexões críticas dizem respeito novamente ao capitalismo (o que, de certo, não é evidente). Afinal, queremos saber o que exatamente estamos criticando, quando, por exemplo, atentamos para uma ordem econômica mundial injusta. Além disso, para as conhecidas

\footnotetext{
1 A palavra falsch, em alemão, pode significar tanto falso como errado. Para explicitar o diálogo que estabelece com Charles Taylor e Philippe Van Parijs, Rahel Jaeggi sugeriu que o termo fosse traduzido por errado e não por falso. Contudo, como não há um termo com o mesmo radical para a tradução de Falschheit, optamos por vertê-la por caráter errôneo (N da T).

2 Para esse esclarecimento da questão inicial, ver: VAN PARIJS, P. What (if anything) is intrinsically wrong with Capitalism? Philosophica 34, 1984 (2), pp.85-102.
} 
estratégias de “delimitação" ou “domesticação" do capitalismo, poderia ser ainda mais decisivo não tratar o sistema econômico apenas como uma caixa preta, e sim perguntar de modo mais exato se há algo na constituição e na dinâmica desse sistema que se opõe a uma delimitação ou ao seu "enquadramento" democrático em instituições compensatórias orientadas pela justiça. Com abordagem caixa preta, me refiro à tendência de falar apenas de como a riqueza, que é produzida no interior de um sistema econômico, teria de ser distribuída, mas não de como ela é produzida e qual tipo de riqueza deve ser produzido.

\section{O que é capitalismo?}

Apenas para adiantar de modo curto e tético, o conceito de "capitalismo" designa aqui, em conexão com minhas considerações, um sistema social e econômico, isto é, abarca a totalidade das dimensões econômicas, sociais, culturais e políticas que moldam as formas de vida em sociedades constituídas pelo capitalismo.

No contexto que aqui nos interessa, "capitalismo" designa uma ordem econômica e social que se desenvolveu historicamente na Europa no final da Idade Média, com a substituição da ordem feudal, e se tornou mundialmente dominante nos séculos XVIII e XIX como capitalismo industrial, com um alto nível tecnológico e vinculado a uma concentração significativa de capital. De um ponto de vista sistemático, os seguintes aspectos apresentam-se como característicos do modo de produção capitalista e das sociedades moldadas pelo capitalismo: (1) a propriedade privada dos meios de produção bem como a separação entre os produtores e os meios de produção, (2) a existência de um mercado livre de trabalho e (3) a acumulação de capital e, como consequência, a orientação para a valorização do capital, isto é, para o lucro e não para a necessidade, para o incremento do capital e não para o consumo ou para a subsistência. (4) Em uma sociedade capitalista, o mercado funciona tipicamente como mecanismo de coordenação de alocação e distribuição de bens (isto é, de distribuição de recursos como trabalho, capital, terra e matérias primas entre as diferentes possibilidades de uso na produção de bens, por um lado, e de sua distribuição para os consumidores individuais, por outro lado); capitalismo e economia de mercado estão, assim, estreitamente relacionados entre si, ainda que não sejam idênticos.

\section{Três Dimensões da Crítica}

Qual é então o problema com o capitalismo? Quando deixamos de lado, de uma vez, as acusações banais contra a ganância do indivíduo, três modelos de argumentação se diferenciam, a saber, três estratégias de critica.

1. Uma estratégia argumentativa funcional: o capitalismo, como sistema social 
e econômico, não pode funcionar; ele é intrinsecamente disfuncional e tende necessariamente à crise.

2. Uma argumentação moral ou orientada à justiça: o capitalismo é baseado na exploração. Ele oculta das pessoas, de modo desigual [unfaire] e injusto [ungerechte], os frutos de seu trabalho e as coage à servidão de um sistema que as engana de diversas formas sobre aquilo que lhes cabe. Dito sucintamente (e de modo menos dramático): o capitalismo se baseia em uma estrutura social injusta ou a produz.

3. A crítica ética: a vida moldada pelo capitalismo é ruim - por exemplo, uma vida alienada [entfremdetes]. Ela é empobrecida, sem sentido ou vazia e destrói componentes essenciais daquilo que pertence a uma vida realizada, feliz, mas também, acima de tudo, a uma vida humana "verdadeiramente livre".

Essas três estratégias argumentativas, que já podiam ser encontradas no início do capitalismo e da crítica do capitalismo, tiveram conjunturas muito diferentes. ${ }^{3}$ Ora, é preciso perguntar a respeito de cada uma dessas linhas argumentativas se ela é convincente, isto é, se ela pode contribuir em algo para uma renovação da crítica do capitalismo sob condições atuais. Simultaneamente, surge a questão: se e como estão vinculados esses aspectos do capitalismo, isto é, essas dimensões de sua crítica. Minha opinião é a de que é justamente a inter-relação entre as dimensões do capitalismo, distinguidas aqui por mim, ou as possíveis críticas a ele, que é instrutiva, de tal forma que os aspectos indicados podem, justamente em sua relação, ser apropriados para sustentar uma crítica do capitalismo enquanto capitalismo. Vou perseguir essa suposição efetivamente apenas na última parte de meu artigo. Primeiramente, gostaria de elucidar um pouco melhor as três estratégias de argumentação e, com isso, tentar indicar seus momentos produtivos bem como suas limitações.

\section{Sobre o teorema do déficit funcional}

Começo pela crítica funcional. A estratégia "funcional" de argumentação afirmava: o capitalismo não funciona como sistema social e econômico. Ele é intrinsecamente disfuncional e tende necessariamente à crise.

A versão teórica mais despretensiosa (mas também aquela que, empiricamente, é mais facilmente contestável) de tal crítica é o simples teorema da crise da teoria da

3 Nas fases de prosperidade, é a problemática ética que parece estar em primeiro plano. Em fases de estagnação ou recessão (como atualmente), teorias da crise que, tal como se acreditava, teriam desaparecido, são inesperadamente retomadas. Interessantemente, todos esses aspectos foram abordados por Marx e, já para ele, dependiam uns dos outros, mesmo que as vezes de modo obscuro. 
pauperização. Como diagnosticado em um momento não tão distante de sua origem, o capitalismo não conseguirá garantir a longo prazo a alimentação dos indivíduos, por meio de processos de concentração econômica e racionalização, criados para sua subsistência. A consequência do desenvolvimento da economia capitalista será, assim, a pauperização permanente e cada vez pior de massas sempre maiores da população que levará, por fim, ao colapso do sistema. O teorema das crises sistemáticas de venda e produção já é mais complexo. O teorema marxista da queda tendencial da taxa de lucro é certamente o mais ambicioso; de acordo com ele, a dinâmica capitalista se autodestrói, de certo modo, por meio das alterações na chamada "composição orgânica do capital” (isto é, na relação entre trabalho vivo e maquinaria). Mas também é possível argumentar a partir de déficits funcionais fora do quadro teórico indicado acima, como, por exemplo, na afirmação de que também a "mão invisível” do mercado ideal não é capaz de garantir a produção de bens públicos, da qual ele simultaneamente depende. Talvez não seja sem importância ressaltar, nesse ponto, que a "crítica funcional" do capitalismo não se reduz a cenários de crise econômica. Como exemplo, também a tese de que o capitalismo destrói sistematicamente as disposições psíquicas e cognitivas necessárias ao seu desenvolvimento e conservação, como a defendida por Daniel Bell ${ }^{4}$ (mas também por Joseph Schumpeter), argumenta, nesse sentido, evidentemente com um déficit funcional.

Ora, essa estratégia funcional de argumentação possui vantagens perceptíveis. Dentre outras, ela é atrativa porque, como figura crítica, parece poder prescindir de critérios que requerem fundamentação: algo que não funciona não é apenas claramente inútil. Algo que não funciona por motivos que estão nele mesmo e que destrói sua própria possibilidade de funcionamento refuta a si mesmo. Tal nãofuncionamento dá motivo para a suposição de que, a longo prazo, o problema vai se resolver ou suprimir a si mesmo.

Pode-se, sem dúvida, afirmar que muitos dos teoremas abordados acima foram refutados, algo que foi feito também muitas vezes, mesmo que a atual crise financeira e econômica tenha dado ensejo à questão: se a afirmação de que o capitalismo "sai bem sucedido de todas as crises", como por vezes se diz, vai realmente se mostrar plausível. Aqui, contudo, não quero me ocupar da refutação dos cenários de crise no que se refere a seu conteúdo, mas iluminar um pouco melhor a própria estrutura desse modo funcionalista de argumentação, para indicar os déficits de tal argumentação (já contidos nela).

4 Ver BELL, D. Die kulturellen Widersprüche des Kapitalismus. Frankfurt am Main: Campus Verlag, 1991. 


\section{Estrutura dos déficits funcionais}

O que é, afinal, um déficit funcional? Que algo seja funcionalmente deficitário significa que ele não funciona como deveria; que ele não funciona como prometido ou que não funciona tal como seria necessário para executar sua tarefa. A tarefa de uma faca é cortar. Uma faca cega não funciona, na medida em que ela não corta.

Asuposição de um déficit funcional sistemático diz respeito à mera circunstância fática de que algo não funciona como deveria, com o que se quer dizer que ele não pode funcionar, por motivos sistemáticos. Não se trata de um déficit que surge frequentemente ou repetidamente. Algo que não funciona sistematicamente, não funciona porque the faltam as condições para realizar a função que dele se espera. Uma faca que não possui uma lâmina ou cuja lâmina seja de massinha foi construída de modo errado para a tarefa que lhe foi atribuída. Falta-lhe uma condição importante para seu funcionamento como faca (para cortar). Nesse sentido simples, trata-se aqui de um não-funcionamento sistemático - e não apenas casual ou empiricamente contingente.

A formulação mais forte (e, poderia-se dizer: “dialética”) desse nãofuncionamento sistemático é, no entanto, constituída ainda de outra forma. 0 teorema pode ser descrito de tal modo que o não-funcionamento do objeto pertença, nesse caso, ao seu funcionamento. Ou: o não-funcionamento é o outro lado do funcionamento. Algo funciona então de um modo que, ao mesmo tempo, destrói seu funcionamento, isto é, mina os fundamentos de seu próprio funcionamento. Ora, isso soa um tanto nebuloso e paradoxal; gostaria de defender, contudo, que é possivelmente isso o que a análise marxista tem em vista, uma vez que se refere ao capitalismo como um sistema disfuncional de organização social e econômica. ${ }^{5}$ Agora, essa compreensão (“dialética”) do não-funcionamento, naturalmente, tem seus riscos.

\section{Problemática da crítica funcional}

A seguir, se esclarece o caráter problemático de tal crítica funcional: em primeiro lugar, bem vistas as coisas, de modo algum se trata de afirmar que o objeto descrito, vale dizer, o sistema descrito, que em seu funcionamento parece destruir seu próprio funcionamento, funciona e não-funciona em um mesmo aspecto. Essa impressão surge apenas porque diferentes aspectos, que são distinguíveis, são aqui reunidos. Pode-se dizer (no caso do sistema econômico capitalista) que algo funciona aqui - agora - de tal forma que a longo prazo - no futuro - não vai mais funcionar. A exploração exaustiva de recursos naturais seria um exemplo disso. Agora, ela nos permite uma certa prosperidade, mas parece ameaçar as condições futuras da vida

5 Seria também sem sentido acusar o capitalismo de não funcionar em todas as suas produções e realizações, isto é, em nenhum aspecto. 
humana. Ou: algo funciona em um determinado aspecto, mas um outro se opõe a ele. É difícil contestar, por exemplo, que em sociedades organizadas em termos capitalistas existe pobreza e riqueza, que, portanto, o desenvolvimento econômico dinâmico vinculado à modernização capitalista certamente gerou riquezas incríveis, mas que essa prosperidade não beneficiou a todos igualmente. ${ }^{6}$

Contudo, com o desmembramento de tais aspectos, mostra-se que não é tão fácil, como parece, defender a tese da disfuncionalidade sistemática e da "autodestruição" do sistema social e econômico capitalista. Pois, se os aspectos que precisam, de fato, ser diferenciados a cada momento foram "alocados" no que se refere ao funcionamento, então é possível afirmar que o déficit funcional (do capitalismo) criticado só existe porque nós exigimos dele a solução de problemas que não estão necessariamente vinculados entre si. ${ }^{7}$ Esse problema seria talvez a exigência não só por um desempenho econômico dinâmico, mas também por uma redistribuição mais igualitária de seus resultados, ou a aceitação de que o capitalismo não tem de se preocupar apenas com o presente, mas também com o futuro, etc. Veja bem: não quero pôr em questão, nesse ponto, que seria desejável viver em uma sociedade que satisfizesse essas exigências, mas apenas colocar em dúvida se podemos ou devemos perseguir esses desejos ou exigências pela via da crítica funcional, analisada por mim aqui.

A seguir, o principal resultado de minhas reflexões até o momento: a crítica funcional apresentada aqui valida aspectos que consideramos decisivos; ela une esses aspectos e, com isso, faz com que também as determinações dos fins e as decisões axiológicas sejam inevitáveis. Isso está relacionado a um ponto que diz respeito a toda a discussão acerca do funcionamento: as coisas funcionam sempre em relação à algo - a saber, em relação a uma determinada função. Também a faca funciona (ou não funciona) em relação ao cortar. No tocante à faca, essa função é tomada como algo, de certo modo, indiscutivelmente inerente a ela. Além de cortar, para o que uma faca deve ser boa? ${ }^{8}$ Agora, no que se refere ao capitalismo, é menos claro qual deve ser sua função. Em geral, "funções" e "funcionamentos" relativos a fatos sociais não estão indiscutivelmente dados, isto é, não estão "instalados" em algum lugar. Ou, dito de outro modo: funções que dizem respeito a condições sociais não são imediatamente inerentes, nem estão dadas sem interpretação.

Mas, se também os déficits conhecidos de um objeto são déficits relativos

6 Certamente, isso vale ainda mais se tirarmos o olhar do "centro" do desenvolvimento capitalista e o voltamos, por assim dizer, para sua - se esta de fato o é - "periferia"!

7 Além disso, os protagonistas do sistema econômico capitalista não prometeram essa solução em absoluto, a saber, nem no capitalismo "como tal", isto é, sem condições adicionais, nem absolutamente com leis.

8 Deixo aqui em aberto essa possibilidade de seu não funcionamento, por exemplo, no que diz respeito a uma obra de arte. Aqui uma faca com a lâmina de massinha não seria disfuncional. Mas ela participa de seu próprio significado, bem como na função original do cortar. 
às funções que atribuímos a ele e se, além disso, não é possível derivar, pelo menos em relação a "objetos" específicos, suas funções diretamente de seu "modo de ser”, então o critério do não-funcionamento depende de outros critérios (como: a atribuição de funções).

\section{O caráter normativo do não-funcionamento}

O critério do funcionamento ou do não-funcionamento não é, portanto, "independente". A destruição das condições futuras à vida humana só é então um déficit funcional se a tarefa de possibilitar também a vida futura for atribuída à economia atual (em vez de dizer: "os últimos serão mordidos pelos cachorros") ${ }^{10}$. Formulado de modo mais geral: o capitalismo não só não implode simplesmente por si mesmo. Ele também não simplesmente não funciona. Uma vez que ele não funciona, ele não funciona com respeito a determinados objetivos e às decisões axiológicas e normas ligadas a eles. Somos nós que tomamos essas decisões axiológicas e normas como base de nossa reflexão. A indicação de um déficit funcional só pode, portanto, ser considerada, se seu não-funcionamento é, desde sempre, entendido como um não-funcionamento de caráter normativo. Mesmo que no capitalismo a produção da pobreza e da riqueza estejam necessariamente relacionadas, disso não resulta qualquer "contradição" que esteja automaticamente associada a uma disfuncionalidade do sistema. A simultaneidade da pobreza e da riqueza só se torna uma contradição sob determinadas condições e a situação evocada por ela só se torna disfuncional quando ela - normativamente pré-caracterizada - é entendida como um escândalo. Enquanto a reação dos participantes também pertence ao nãofuncionamento de um sistema social, esse componente normativo é evidente: a "plebe" produzida pela ameaçadora integração social e pela dinâmica econômica burguesa não é, como na famosa análise de Hegel do "opressivo problema da pobreza na sociedade civil”, simplesmente pobre, ela está indignada. E é essa indignação, juntamente com suas consequências, que está em posição de ameaçar a coesão da sociedade.

Talvez haja, em algum lugar, limites definitivos para a capacidade funcional. Mas, de certo modo, também "funcionam" as sociedades (como podemos estudar em um desenvolvimento mais amplo) em que as classes altas e até mesmo as classes médias só podem se sentir seguras em comunidades muradas, ou em que inversamente - uma parcela não insignificante da população passa sua vida atrás de grades, isto é, uma sociedade em que os pobres estão trancados dentro ou fora. Se somos da opinião de que essa sociedade não funciona como sociedade, isso se deve

9 Minha tese é, então, a de que: isso vale (pelo menos) para todas as entidades sociais.

10 “Den Letzten bissen die Hunde". Trata-se de um ditado alemão que significa que os últimos sofrerão as consequências desagradáveis de algo ( $\mathrm{N}$ da $\mathrm{T})$. 
exatamente ao fato de que achamos que ela não funciona bem, isto é, de que ela não deveria funcionar desse modo. Consideramos determinadas formas de funcionamento como erradas - por exemplo, uma dinâmica econômica que funciona às custas do futuro ou dos excluídos. Uma sociedade atrás de grades não condiz com a nossa representação daquilo que a sociedade é ou deveria ser. As crises funcionais (do capitalismo) são sempre também crises normativas. Isso significa: se o capitalismo, como sistema social e econômico, ameaça entrar em colapso - uma posição da qual alguns parecem partir hoje novamente -, esse colapso está sempre ligado ao fato de que nós não queremos viver assim, dessa determinada forma - e não que não se poderia viver assim.

\section{Avaliação do modelo de crítica funcional}

Algumas das evidências que parecem fazer da crítica funcional uma boa candidata para a crítica do capitalismo são então, de certo modo, duvidosas - isso se segue de minha discussão até aqui. Se a tese funcional obtinha sua atratividade da crença de que poderia prescindir de um horizonte normativo - se algo não funciona, ele não funciona e isso parece ruim mesmo sem outro motivo razões adicional -, agora, ela se apresenta, de sua parte, como dependente de um horizonte normativo, isto é, de posições sobre de que maneira algo deve funcionar. Se nos perguntamos, por conseguinte, em que medida a crítica funcional satisfaz as exigências de nossa questão inicial, se ela pode fornecer critérios convincentes para identificar o caráter intrinsecamente errôneo do capitalismo, então é válido afirmar o seguinte:

- Uma argumentação funcional - caso ela esteja certa - preenche de modo preciso a exigência de revelar uma problemática sistemática e específica do capitalismo. Mas, mesmo que consiga identificar essa característica estrutural do capitalismo em termos de crise, ela ainda padece do problema de que, com um argumento funcional constituído dessa forma, não é possível simplesmente se esquivar da questão normativa acerca de por que o capitalismo é errado. Ela permanece, portanto, dependente de critérios normativos, mas, na medida em que não os explicita, deixa-os sem demonstração. .

- Ora, isso não quer dizer que o momento funcional e a questão acerca das possíveis disfuncionalidades do sistema social e econômico capitalista sejam inteiramente inúteis ou sem importância. Mesmo que tal análise, como argumentei, não possa simplesmente substituir uma avaliação normativa, a tomada de posição normativa não diz respeito, por fim, ao "material" que, enquanto tal, resulta de reflexões orientadas por questões funcionais. Portanto, mesmo que os critérios da sustentabilidade ecológica e a questão da justiça distributiva sejam levados por nós ao sistema econômico capitalista, 
isso ocorre em razão de análises que nos mostram que e porque tais pontos de vista são hoje frustrados pelo sistema.

Na minha opinião, no entanto, o significado do elemento funcional e da "crítica funcional do capitalismo" se estende ainda mais; ele diz respeito a um ponto sistemático central. Acredito (e vou voltar a isso novamente abaixo) que, por princípio (isto é, já em um nível conceitual fundamental), é preciso pensar conjuntamente o momento normativo e o funcional, em suas direções, e representálos como entrelaçados um ao outro. Formas de vida socioculturais e instituições sociais são, de modo geral, estruturas que não se caracterizam apenas pelo fato de que podem, em geral, entrar em crises. Elas entram - é isso que quero defender - em crises que, de modo característico, são sempre também crises normativas. Porém, inversamente, crises normativas sempre possuem também um aspecto funcional: elas são normativas e são crises, isto é, são também funcionalmente deficitárias; elas se expressam, portanto, em rejeições e problemas práticos. Mesmo que a referência a um déficit funcional dependa de um elemento normativo, não é trivial, por exemplo, a referência à destruição das condições de existência. Permanece uma diferença entre observar a pobreza como um problema de desintegração produzido pela própria sociedade civil, da mesma maneira que Hegel o fez, ou como um escândalo moral.

Voltemo-nos agora às duas outras formas de crítica do capitalismo que, em oposição à argumentação funcional, possuem uma postura normativa mais ou menos clara, uma avaliação da situação (como certa ou errada). Conforme já exposto acima, essa crítica normativa do capitalismo tem, por sua vez, duas versões, cuja diferença precisa ser explicada. Se um dos motivos pode ser atribuído de modo grosseiro à temática frequentemente qualificada pela questão acerca da boa vida, a outra parece remeter ao problema moral da injustiça (em sentido rigoroso). ${ }^{11}$

\section{Crítica moral do capitalismo}

De início, vou me ocupar da crítica moral ou orientada à justiça do capitalismo. Com isso, discutirei o que podemos entender como o elemento referente à teoria da justiça em Marx - no lugar de teorias modernas da justiça, porque essas não se apresentam como crítica do capitalismo, mas, quando muito, têm (podem ter) consequências críticas ao capitalismo.

O que diz exatamente essa crítica? A argumentação moral ou orientada à justiça objeta, contra o capitalismo, que ele se baseia na injustiça, a saber, que produz

$11 \mathrm{Em}$ "O novo espírito do capitalismo", Botanski e Chiapello opuseram a "crítica artística" à "crítica social". Cf. BOLTANSKI, L; CHIAPELLO, E. Der neue Geist des Kapitalismus. Konstanz: UVK Universitätsverlag Konstanz, 2003. 
e reproduz uma estrutura social injusta. Se buscamos uma tal dimensão da crítica do capitalismo, então estamos próximos de vinculá-la ao teorema da exploração. A indignação com a exploração, tanto em Marx quanto na compreensão cotidiana, corresponde na maior parte das vezes à argumentação contra o capitalismo nos termos de uma teoria da moral ou da justiça. - ou, em todo caso, parece corresponder a ela na maior parte das vezes. ${ }^{12}$

O capitalismo - de acordo com essa crítica - explora então as pessoas, na medida em que oculta delas de forma desigual [unfaire] e injusta [ungerechte] os frutos de seu próprio trabalho e as coage, de modo extorsionário, à servidão de um sistema que as engana, de diversas formas, sobre aquilo que lhes cabe.

Ora, não quero examinar mais uma vez a validade empírica dessa argumentação, que possui um forte poder de mobilização e, em vista de muitos fatos, pode reivindicar grande plausibilidade para si, mas tratar dos riscos desse modo de argumentação enquanto tal.

O problema dessa estratégia reside já na conceitualização de exploração, mas remete, com isso, a um problema conceitual da própria crítica moral do capitalismo.

- Ou entendemos a exploração da maneira que nos sugerem as instituições morais cotidianas: neste caso, ela é, como denominou Bernard Williams, um "conceito forte [thick concept]", isto é, um conceito em que avaliação e descrição estão inseparavelmente vinculadas entre si, de tal forma que não faz sentido algum perguntar, no que diz respeito a ele, o que pode haver de errado com a exploração. Intuitivamente plausível e moralmente defensável, esse conceito de exploração levanta, se quisermos fazer dele o critério da crítica, a questão: trata-se realmente de um problema específico do capitalismo ou “apenas" do fato de que também há exploração no capitalismo?

- A variante marxista do conceito de exploração, por outro lado, funciona de modo conhecidamente distinto. Aqui, o conceito de exploração é um conceito técnico-analítico que deve descrever como funciona a forma da economia capitalista. Exploração é a absorção do excedente da produção. Esse conceito de exploração, que é diretamente talhado para compreender, de modo específico, as relações capitalistas, padece evidentemente do seguinte e notório problema: na medida em que apenas descreve o modo de funcionamento do capitalismo em geral, ele não parece estar em posição de criticá-lo como normativamente (ou moralmente) deficitário.

12 Da mesma forma, a teoria da justiça, na linha da de Rawls, pode sem dúvida ter consequências críticas ao capitalismo, mas ela não se coloca como uma crítica do capitalismo. Por isso, me parece fazer sentido começar desse modo e me fixar em um suposto elemento da crítica do capitalismo baseado na justiça - e particularmente: em Marx. 
Para elucidar essa problemática, investigarei primeiro o que é a exploração em geral - de acordo com nossa compreensão prévia. Depois, elucidarei o papel do conceito de exploração em Marx. Por fim, quero mostrar que as dificuldades do conceito de exploração (em Marx), a saber, as dificuldades de sua classificação normativa, só podem ser resolvidas quando a perspectiva é alterada e a exploração é entendida, ante o pano de fundo mais específico e mais amplo do capitalismo como forma de vida. Dito em termos hegelianos, é assim a "eticidade capitalista" (isto é, a não-eticidade) que está na mira da crítica marxista. É somente a partir do pano de fundo dessa perspectiva que o "fracasso moral" do capitalismo pode ser compreendido. Desse fato, é possível extrair conclusões para as perspectivas de uma crítica moral do capitalismo ou indicar alguns problemas gerais dessa abordagem.

\section{Exploração em geral (compreensão cotidiana)}

A compreensão cotidiana da exploração abrange instituições amplamente difundidas: trabalho infantil é exploração. Aquele que produz seus produtos nas fábricas clandestinas dos empobrecidos países em desenvolvimento (ou compra tais produtos), lucra com a exploração da população local. Um terapeuta que inicia uma relação sexual com uma paciente, a explora emocionalmente. Mas também fenômenos como prostituição e barriga de aluguel estão na mira da crítica como potenciais relações de exploração. Essa breve enumeração de momentos (mais ou menos controversos) de exploração já mostra a complexidade do conceito de exploração. Numa primeira aproximação, a discussão sobre "exploração" parece mesmo implicar o seguinte:

- Que alguém seja explorado significa, por um lado, que ele não recebe aquilo que ele merece - no sentido de uma ideia de troca justa. A exploração denota, nesse caso, a inadequação quantitativa de uma relação de troca. ${ }^{13}$

- Trabalho infantil não é, contudo, apenas muito mal pago; também a suspeita de que a "maternidade de aluguel" pode ser tomada como uma relação de exploração não diz respeito principalmente à remuneração financeira inadequada. Aqui, a suspeita ligada ao conceito de exploração é, pelo contrário, a de que há uma relação de troca onde não deveria haver uma. A exploração, pelo menos assim parece, corresponde nesse caso à inadequação qualitativa de uma relação de troca, que podemos soletrar com os termos da instrumentalização, do desrespeito ou também da reificação.

13 Se essa inadequação é determinada absoluta ou relativamente não desempenha aqui qualquer papel, ainda que, por motivos que vou expor abaixo, a determinação relativa me parece mais plausível, uma vez que a exploração diz respeito a uma relação social e não a uma carência natural. 
- Por fim, em todas essas relações está em jogo uma forma de assimetria e uma distribuição desigual de poder.

Agora, o que significa tudo isso para uma crítica do capitalismo ligada à exploração? Se ela estiver atrelada a essa (complexa) compreensão cotidiana, então parece claro, ao menos até certo ponto, em que medida o capitalismo poderia ser um mal (moral) - uma vez que ele pode ser acusado de incluir a exploração. Já mencionei acima que esses fatos e fenômenos tiveram e têm um forte poder de mobilização para os movimentos críticos do capitalismo. Contudo, não está claro se se trata de um mal específico do capitalismo. Trabalho infantil, tráfico de escravos e outras graves formas exploradoras de opressão ou desrespeito existiam também em sociedades pré-capitalistas. Por fim, os defensores do livre mercado não ficarão cansados de enfatizar que, também a seu ver, os deploráveis excessos da globalização capitalista (fábricas clandestinas, trabalho infantil) não deveriam ser atribuídos ao próprio mercado, mas ao fato de que o mercado capitalista ainda não está completamente estabelecido.

Se alguém quiser partir da crítica moral ligada à exploração, então deveria mostrar que mesmo as relações não caracterizadas por esses gritantes e evidentes fenômenos de miséria e exploração se baseiam na exploração, mostrar que elas também existem para além dos cenários Oliver-Twist - que, infelizmente, também são ainda hoje muito reais - e, acima de tudo, que existe uma forma específica de exploração no capitalismo que vale a pena criticar. Portanto, não basta apenas afirmar que também o capitalismo explora os homens - da mesma maneira que, antes dele, a sociedade feudal ou a antiga sociedade escravagista -, mas que isso ocorre de forma sistemática e de um modo específico, distinto de outras relações. ${ }^{14}$ Exatamente por esses motivos é interessante recorrer ao conceito de exploração de Marx que, podese supor, é dirigido especificamente ao capitalismo e se ocupa justamente da questão do caráter sistemático-necessário da exploração e da injustiça.

\section{Exploração em Marx}

No que concerne à ambiguidade da compreensão de Marx em relação à exploração, já foi assinalado: por um lado, ela também parece se juntar à compreensão esboçada acima. Se Marx clama pela "revolução de todas as relações em que o homem é humilhado, escravizado, abandonado e desprezado", então é difícil não reconhecer que se expressa aqui uma indignação moral. A exploração é

14 Para esclarecimento, novamente: para uma crítica de tais relações, certamente também basta o fato de que se explora em geral (independentemente se de modo específico ou não específico). Mas meu questionamento se dirige aqui à questão de se há uma dimensão associada especificamente ao capitalismo que justifica, da mesma forma, uma crítica específica a ele. A saber, a questão de se há males que sejam intrinsecamente ligados a ele. 
um dos males que as pessoas experienciam de pessoas. Uma ordem social que se baseia nesse mal ou o promove merece ser criticada. Por outro lado, diferentemente da compreensão cotidiana esboçada por mim, para Marx “exploração” é também um conceito técnico-analítico, que coincide apenas parcialmente com o uso cotidiano do conceito. Ante o pano de fundo da teoria marxista do valor-trabalho, a exploração é entendida como apropriação do excedente do trabalho do trabalhador pelo capitalista, como apropriação daquilo que o trabalhador conseguiu por meio de seu trabalho para além do que é necessário para a reprodução de sua força de trabalho, ou enquanto apropriação da mais-valia. A escala da exploração resulta da diferença entre o tempo de trabalho diário real e o tempo de trabalho diário necessário para a reprodução da força de trabalho, o grau de exploração é medido pela taxa de maisvalia, pela relação entre o excedente de trabalho e o trabalho necessário, trabalho pago e trabalho não pago. Mas, exatamente por isso, a exploração não é um roubo no capitalismo. Ela não se baseia em relações abertas de dominação ou em violência direta, mas sim na coerção indireta das circunstâncias.

\section{Ambiguidade normativa do conceito de exploração}

Ora, essa compreensão da exploração possui, dentre outras, as seguintes consequências: não somente o deplorável trabalho infantil (relações como as que Marx já havia realmente encontrado), mas também o trabalho assalariado absolutamente normal é - de acordo com essa análise - exploração. No sentido técnico esboçado acima, contudo, a "exploração" não é certamente um escândalo moral, mas simplesmente descreve o modo de funcionamento do capitalismo. A exploração seria então apenas uma descrição neutra justamente daquilo que o capitalismo faz, de acordo com suas condições de funcionamento, na medida em que é capitalismo. ${ }^{15}$

Quando Marx descreve então a exploração como absorção do excedente da produção e, portanto, como relação, que é inerente a todo trabalho assalariado que produz mais-valia, isso significa uma banalização [Entdramatisierung] do conceito de exploração ou, ao contrário, uma dramatização [Dramatisierung] do mal ocasionado pelo trabalho assalariado? Será que Marx pôde chegar aqui ao fundamento do caráter específico da exploração do capitalismo, mas para isso deixou a exigência de crítica dessas relações escapar, por assim dizer, por entre seus dedos? ${ }^{16}$

Temos de nos confrontar com o fato de Marx afirmar, de maneira confusa, que o modo de produção analisado por ele não é, em si, injusto. "Em si”, isto é, se

150 filósofo americano Allen Wood defende decididamente que, segundo Marx, a exploração média, isto é, a "exploração normal" no capitalismo, não seria injusta. Cf. WOOD, A. W. Karl Marx. London: Routledge, 1981.

16 Sobre a relação entre Marx e moral, conferir o ainda hoje importante volume de ensaios em língua alemã: ANGEHRN, E..; LOHMANN, G. (orgs). Ethik und Marx, Moralkritik und normative Grundlagen der Marxschen Theorie. Königstein/Ts: Hain bei Athenäum: 1986. 
aceitamos as condições e os pressupostos fundamentais da economia capitalista aqui, eu entenderia isso assim -, não se verifica qualquer problema e, portanto, nada a criticar. Mas, resulta disso então, realmente, apenas a conclusão de que, segundo Marx, a exploração não deve ser uma relação normativamente problemática, digna de crítica? ${ }^{17}$

Considero isso implausível. A fim de compreender o status (normativo) da explicação marxista sobre a exploração e também o ponto de vista normativo a partir do qual Marx critica, de fato, o capitalismo, é importante lembrar qual é o contexto em que ela se encontra, isto é, face a quais pressupostos e em que situação opera a crítica marxista do capitalismo.

\section{Dominação coisificada.}

Marx quer esclarecer - é possível compreender o projeto da "crítica da economia política" assim - os efeitos contínuos da dominação e da exploração sob o invólucro objetivo da economia capitalista e das relações contratuais da sociedade civil. Pois, se a verdadeira inovação institucional da economia capitalista é a existência de um mercado livre de trabalho, e se esse caracteriza por estar baseado em contratos livremente estabelecidos e na ideia de equivalência (trabalho em troca de salário, salário na qualidade de remuneração do trabalho em vez de trabalho compulsório ou imposto compulsório), então é difícil concluir, à primeira vista, em que medida essas relações podem ser tomadas como relações de exploração. Mesmo se levamos em conta a situação miserável do operariado no capitalismo nascente: nem o caráter coercitivo (a ausência de livre arbítrio) ou a desigualdade das relações estabelecidas aqui são evidentes sob relações da sociedade civil (da socialização do mercado burguês-capitalista).

Consequentemente, Marx analisa a exploração como uma relação (mesmo que sutil) de dominação ou coerção. 0 "caráter técnico" de sua análise reage à sutileza dessa relação e ao caráter estrutural e impessoal da coerção envolvida. Mas justamente esse fato nos dá a possibilidade de entender a diferença, de início um tanto confusa, entre nossa compreensão cotidiana, com seu significado claramente moral, e a compreensão marxista descrita há pouco (em sua ambiguidade).

\section{Significado moral ou ético do conceito de exploração?}

Minha tese é a de que o problema do caráter crítico-normativo da teoria

17 Sobre as dificuldades de identificar o problema normativo da exploração em Marx, ver VAN PARIJS, P. What (if anything) is intrinsically wrong with Capitalism?. A posição de que que a exploração é utilizada de modo normativamente neutro é defendida por Wood. Cf. WOOD, A. W. Karl Marx. Em contraposição a ela: WILDT, A. "Gerechtigkeit in Marx' ,Kapital'”. In: ANGEHRN, E.; LOHMANN, G. (Hrsg.). Ethik und Marx, Moralkritik und normative Grundlagen der Marxschen Theorie. Königstein / Ts.: Hain bei Athenäum, 1986, pp.149-173. 
marxista da exploração (e sua surpreendente rejeição de implicações morais) só pode ser resolvido se não tentamos interpretar a crítica marxista como uma crítica moral, em sentido rigoroso ${ }^{18}$ (ou como uma crítica fundada nos termos da teoria da justiça, em sentido rigoroso), mas em vez disso a compreendemos como uma crítica eticamente inspirada. Uma crítica que diz respeito à forma de vida do capitalismo em seu todo e, com isso, às relações que são responsáveis pela estrutura de dominação coisificada e pela coerção invisível que possibilitam, por sua vez, um modo específico de exploração.

Portanto, errado não é, de fato, o modo de produção baseado na exploração (do excedente da produção) em si. Ele funciona exatamente assim e é incontestável segundo seus próprios critérios - internos - de justiça. Mas, que ele funcione desse modo é, ainda sim, um problema: porque errado é o próprio modo de produção. Porém, esse caráter errôneo não é então constituído, e isso é decisivo, senão como o caráter errôneo da troca injusta ou da distribuição desigual [unfairen]. Não se trata mais de uma injustiça em sentido rigoroso, mas de uma "injustiça" num sentido abrangente, ${ }^{19}$ que diz respeito ao todo da forma de vida que possibilitou, primeiramente, essa dominação coisificada e a dinâmica coercitiva descrita. ${ }^{20} \mathrm{~A}$ crítica moral ou nos termos da teoria da justiça, em sentido restrito, deveria, por conseguinte, se envolver na análise e na crítica do capitalismo enquanto modo de produção (e, além disso: enquanto forma de vida), na medida em que quer abordálo como problema específico. Os problemas morais, portanto, não só não têm como ser resolvidos, eles também não têm como ser entendidos se não são vistos da perspectiva da problemática da forma de vida capitalista, enquanto forma de vida. A "injustiça” do capitalismo seria então "abrangente", da mesma maneira que o discurso sobre "direito" na filosofia do direito de Hegel, uma vez que a discussão sobre "direito" abrange aqui integralmente a racionalidade e o bem estar de uma ordem social. O mal específico do capitalismo não é seu caráter injusto e imoral, mas sua não-eticidade (em sentido hegeliano); ele falha enquanto relação ética.

\section{Exploração como "injustiça por excelência"}

Eu concordo aqui com uma das teses de Georg Lohmann que vê, no que diz respeito às "duas concepções de justiça” de Marx: a limitação interna da justiça distributiva e a abrangência da justiça de uma forma de vida enquanto tal, que

18 Sobre as dificuldades de compreender a exploração como injustiça a partir de um viés igualitário, ver VAN PARIJS, P. What (if anything) is intrinsically wrong with Capitalism?

19 Justamente no sentido abrangente em que Hegel, do mesmo modo, falou de "direito".

20 Aqui, Marx está e permanece vinculado à crítica hegeliana da moral e contrário a uma crítica meramente moralizante, como uma instância do mero dever sem apoio na realidade. Analogia: assim como para Hegel a moral é suprassumida na eticidade, para Marx o mal moral está interligado ao mal da eticidade. 
tematiza os fundamentos da distribuição e, com isso, os fundamentos de toda uma forma de vida/modo de produção. Salta então à vista - segundo essa tese - não apenas a não equivalência do salário, mas também uma inadequação qualitativa das relações com o mundo e com o eu, que surge, por exemplo, quando o trabalho é trocado no livre mercado a título de trabalho abstrato. Com isso, no entanto, não é apenas a "dimensão qualitativa" da exploração, exposta acima para a compreensão cotidiana, que é retomada. Em todo caso, no que diz respeito a Marx, parece então se tratar do fato de que a dimensão moral do mal do capitalismo não é, por sua vez, "independente". Ela só pode ser compreendida e incorporada na dimensão "ética" de sua problemática predominante. Logo, não se trata do problema de que os contratos de trabalho, com os quais o trabalho assalariado é comprado e tornado produtivo, não seriam justos ou que eles não seriam cumpridos, isto é, que eles prejudicariam alguém. Isso, sem dúvida, também ocorre frequentemente. Mas, as disputas em torno do salário, das condições de trabalho e as disputas acerca da duração da jornada de trabalho são simplesmente e, sob certo aspecto, parte do jogo, quando ele é jogado por alguém. Não pertence precisamente ao jogo tornar válidos outros pontos de vida úteis que não os interesses dos participantes pelo lucro. Quando se quer aqui criticar algo, então é preciso criticar "o próprio jogo" - por exemplo, o fato de que a força de trabalho é, em geral, comercializada e tratada como coisa. Mas, assim, os limites estritos de uma crítica moral ou nos termos de uma teoria da justiça são ultrapassados (desde que falemos, de uma perspectiva qualitativa, sobre a compreensão básica dos bens disponíveis em uma sociedade).

\section{Resumo para uma crítica moral:}

Das reflexões esboçadas até aqui, resultam três coisas para a crítica moral e para nossa questão inicial. Mesmo se partirmos do fato de que ela foi bem sucedida em identificar os critérios da crítica, e parto disso sem problematizar aqui essa questão mais a fundo, estes permanecem inespecíficos no tocante a seu objeto. Nessa perspectiva, eles seriam então "não isolados" (ante o pano de fundo da natureza da tarefa dada). A fim de torná-los mais específicos e menos desamparados, eles têm de ser inseridos em uma análise da "relação ética", que é o capitalismo, e com isso também em uma análise das condições estruturais dadas com ele, que promovem o resultado problemático em termos morais (e em termos de uma teoria distributiva). Tudo isso culmina em uma perspectiva que Marx tomou de Hegel ao censurar o "dever vazio" e a impotência peculiar de uma crítica moral das relações capitalistas. 


\section{Crítica ética ao capitalismo.}

A crítica ética do capitalismo significa, em diversas variantes, mais ou menos o seguinte: a vida marcada pelo capitalismo é uma vida ruim ou uma vida alienada. Ela é empobrecida, sem sentido ou vazia e destrói componentes essenciais daquilo que pertence a uma vida humana realizada, feliz, mas também, acima de tudo, a uma vida "verdadeiramente livre". Resumidamente: a crítica ética tematiza o capitalismo como relação com o mundo e com o eu. Ela o tematiza tendo em vista a maneira pela qual ele influencia a consumação de nossa vida, nossa relação com nós mesmos, com o mundo e com as coisas. Críticas desse tipo são também tão antigas quanto o próprio capitalismo. ${ }^{21}$

Como sintomas do modo de vida capitalista, que estão aqui em questão, contam, por exemplo, os fenômenos de coisificação e empobrecimento qualitativo de relações de vida, tal como já foram censurados desde o início do desenvolvimento capitalista. No que diz respeito a isso, é possível consultar inventários em Capitalismo Moderno, de Wermer Sombart, onde, em um tom patético, a relação pessoal das camponesas pré-capitalistas com suas vacas é contraposta, de modo decididamente sentimental, à relação coisificada e calculadora do capitalista com a criatura e com as coisas. ${ }^{22}$ Com profundidade de foco completamente distinta (e uma consciência inteiramente diferente da ambivalência), também a Filosofia do Dinheiro de Georg Simmel se ocupa da coisificação como tendência fundamental da vida moderna (marcada pela economia capitalista de troca). Isso também nos ocupa hoje, em dimensões inteiramente inimagináveis, como problema da mercantilização e da comercialização ou comoditização. A crítica feita desde cedo à ganância institucionalizada e à dinâmica incessante do capitalismo contam também como sintomas problematizados pela crítica ética. ${ }^{23}$ Também a perda do espírito e da alma, o empobrecimento e o achatamento do mundo limitado por interesses mercantis em "algo concernente a fins"”, frequentemente foram mais do que apenas objeto de considerações literárias.

\section{Sentido da perspectiva ética}

Eu a considero - bem entendida - uma perspectiva razoável sobre a efetividade das relações capitalistas e também uma via razoável de crítica. Que o capitalismo

$21 \mathrm{E}$, não é o menor dos méritos da teoria marxista - pelo menos eu o entenderia assim -, que ele tenha tirado esse momento da crítica do capitalismo de seu ambiente crítico à modernidade e o transformado. (Embora isso seja, por vezes, contestado).

22 SOMBART, W.DermoderneKapitalismus. Historisch-systematischeDarstellungdesgesamteuropäischen Wirtschaftslebens von seinen Anfängen bis zur Gegenwart. Paderborn: Verlag Schöningh, 1902/2012.

23 Somente um exemplo dentre vários: a contraposição entre as formas de vida próprias ao précapitalismo e ao capitalismo em North and South, de Elizabeth Gaskells. 
também tenha ou seja uma "cultura", que ele molde e promova uma determinada forma de vida, é um fato relevante não apenas no que diz respeito à pergunta sobre o que precisamente faz com que os indivíduos "sofram no capitalismo". ${ }^{24}$

Indiscutivelmente, a força da crítica ética do capitalismo consiste pelo menos no fato de que ela revela uma circunstância que é frequentemente encoberta: trata-se, no capitalismo, de uma forma social e econômica que se baseia em geral em algo como valores, isto é, implica ou produz decisões axiológicas. Assim, por exemplo, fica claro na crítica das tendências de mercantilização que o mercado não é uma instância neutra de distribuição de bens, mas que essa instância oferece a esses bens uma forma determinada.

Por conseguinte, o que as variantes culturais conservadoras e nostálgicas de uma crítica ética do capitalismo ainda explicam, de modo bem sucedido, é o fato de que a esfera econômica - a relação de troca nos mercados capitalistas, por exemplo - não é eticamente neutra. Como e o que é aqui negociado é expressão de uma forma de vida sempre determinada e de uma visão de mundo, que exclui ou ao menos influencia outras formas de vida ou concepções de mundo. Conceber determinadas coisas, capacidades e relacionamentos como "mercadorias" não significa meramente traduzi-las - de modo eticamente neutro - a outro meio. Conceber coisas como objetos alienáveis [entäuBerlichte], trocáveis por outros bens (ou pelo equivalente geral do dinheiro), cria uma concepção bastante determinada de objetos, relacionamentos e capacidades. Quea "mercadoria força de trabalho" (na qual a existência do capitalismo sabidamente se baseia ${ }^{25}$ ) seja concebida exatamente como tal, exatamente como "mercadoria", é tudo menos evidente e tem consequências relativas a nossa relação com aquilo que nós - trabalhando - fazemos.

Mas, parece ser decisivamente característico do capitalismo que ele negue esse caráter axiológico e, com isso, o fato de que se trata de uma forma de vida determinada - que, consequentemente, também pode e tem de ser avaliada e, por conseguinte, também precisa ter alternativas. ${ }^{26}$ Talvez isso já seja uma razão suficiente - seria um tipo de meta-razão - para aceitar que há algo de suspeito no capitalismo. Segundo o mote: "quem oculta algo, tem algo a esconder."

\section{Problemas da crítica ética}

Os problemas dessa crítica ética do capitalismo, em relação aos critérios

24 Tomo como um erro descartar essas questões como problemas de luxo de uma esquerda próspera saturada.

25 Sobre o imperativo do livre mercado de trabalho e sua caracterização, conferir: MARX, K. "Das Kapital. Kritik der politischen Ökonomie. Erster Band. Der Produktionsprozess des Kapitals". In: MARX, K.; ENGELS, F. Werke bd. 1. Mew bd 23. Berlin: Institut für Marxismus-Leninismus beim ZK der SED 1867, pp.181-2 e 189-192.

26 Poderia-se dizer: esse é um tipo de efeito característico da ideologia. 
seguidos até aqui, são, contudo, evidentes:

- No sentido da problemática introduzida acima, acerca do caráter especificamente errôneo do capitalismo, a crítica ética se vê confrontada com o problema de que não é sempre claro quais dos sintomas atribuídos a ela são realmente específicos à natureza capitalista. Trata-se aqui efetivamente do capitalismo ou, antes, da modernidade de modo geral e, em caso de dúvida, de que maneira ambos estão relacionados? A ampliação da economia monetária e do mercado naturalmente influencia a relação com pessoas e com coisas; mas, formas massivas de instrumentalização - pense apenas no tráfico de escravos - certamente também existiram em formações sociais de tipos inteiramente diferentes. Para que as tendências atuais da "ampliação do mercado" (desde a barriga de aluguel até os modernos exércitos de mercenários) possam ser criticadas, seria preciso mostrar primeiro que, sob condições capitalistas, elas assumiram formas específicas e diferentes. Acredito, aliás, que isso é possível, apenas foi feito muito raramente.

- Mais urgente, no entanto, é o problema da identificabilidade dos critérios da crítica em questão. 0 que há de problemático nas características enumeradas por mim? A indiferença do mercado frente às particularidades pode ser criticada como nivelação do heterogêneo - e, com isso, como redução do sentido e da forma do "empobrecimento" - e a alienação [entäuBerung] de determinadas particularidades e capacidades, como objetivação e reificação. A coisificação e despersonalização de relações sociais podem ser estigmatizadas como atomizações e instrumentalizações. Mas, muitos desses diagnósticos possuem uma inclinação crítico-cultural ou pessimista-cultural, os modos de vida precedentes são sempre nostalgicamente romantizados, juntamente com seus produtos, práticas e hábitos. Com a introdução das estradas de ferro, as pessoas estavam convencidas de que sua rapidez levaria inevitavelmente à loucura; hoje, a tranquilidade das estradas de ferro é exaltada como a "experiência genuína e significativa do viajar" frente a aceleração das formas de vida forçada pela EasyJet. No momento de sua introdução, a divisão do trabalho na linha de montagem era sinônimo de trabalho alienado [entfremdete] e disciplinamento desumano; retrospectivamente, o sistema "fordista" de assistência vital já foi praticamente reabilitado como uma união que gera identidade e comunidade, frente à dinâmica desqualificadora e destruidora de identidades e à pobreza da experiência do novo "capitalismo flexível". O princípio da nostalgia, aqui atuante, coloca em dúvida quão estáveis e verificáveis realmente são os critérios atuantes.

No que diz respeito à isso, é contudo ainda mais grave a ambivalência de muitos dos fenômenos considerados pelas críticas éticas do capitalismo. Não é à toa 
que a descrição de Georg Simmels da vida moderna sob o signo da intercambialidade e do dinheiro - uma obra-prima da descrição do capitalismo como forma de vida, que até hoje não foi novamente recuperada - já é manifestamente ambivalente. A saber, a indiferença perante relacionamentos específicos e características intrínsecas aos bens significa também liberdade. A perda de laços proporcionada pelo dinheiro significa também independência. Uma vez que o livre mercado de trabalho - em todos as suas lacunas e brutalidades - substituiu as relações de servidão feudais, o mercado (capitalista) não representa apenas a efetividade (se ele faz isso), ele também representa, como instituição do contrato, um princípio ético: que a liberdade dos modernos, como uma liberdade de escolha, também consiste em viver sua vida de modo independente dos outros.

Essa ambivalência dos fenômenos retratados é mais um indicador de que não é, de forma alguma, fácil determinar os critérios éticos com base nos quais determinados aspectos da forma de vida capitalista poderiam ser recusados com razões. De onde extrair os critérios? Como obter uma crítica promissora do capitalismo e com força combativa, que não recaia em mais um mero (e abstrato) discurso sobre virtudes (o apelo a valores)? Temos de nos libertar da ganância e nos lembrarmos do "verdadeiro": talvez tudo esteja certo, mas contudo desamparado.

\section{Retomada e Resultado}

Buscamos uma crítica que trate especificamente do capitalismo (isto é, como uma organização social e econômica específica), que possa, ao mesmo tempo, ser identificada como normativa. ${ }^{27}$

1. A crítica funcional se mostrou realmente específica (onde é plausível), mas normativamente dependente, uma vez que a identificação de disfuncionalidades permanece ligada à critérios valorativos, que esta não pode gerar ou defender por si mesma.

2. A crítica moral ou nos termos da teoria da justiça, em contrapartida, não é específica ao capitalismo, o capitalismo não é tomado como fonte específica de determinado mal moral. Ora, para essa posição, isso não é necessariamente um problema. Mesmo se assumimos (e esse é o caso aqui, sem que eu tenha tratado ou fundamentado isso especificamente) que seus critérios normativos são válidos, ela incorre na acusação notória (desde de a crítica de Hegel a Kant) de "desamparo do dever moral". A crítica moral não se mostra então como errada, mas em certo sentido como incompleta. Como também é sempre possível avaliar as possibilidades de uma crítica (não moralizante)

270 pressuposto mais tradicional, de que a crítica é sempre dependente do estabelecimento e da verificação de critérios normativos, está certamente implícito aqui, em contraposição às posições que que recorrem apenas à força de ruptura de novas descrições, etc. 
do capitalismo estabelecida imanentemente, tal como Marx a concebeu, pode-se concluir que a crítica moral ou nos termos da teoria da justiça tem uma relação com seu objeto que pode, inicialmente, ser descrita como uma "abordagem caixa preta". Isto é, ela está orientada aos efeitos e não se dirige à dinâmica e constituição específicas das instituições econômicas e sociais, que produzem esses efeitos.

3. A crítica ética, abstraindo de determinadas fraquezas (eventualmente remediáveis) na concepção específica de seu objeto, teve o problema da identificação de seus critérios normativos: um problema que pode, por sua vez, resultar em sua paralização em um discurso (igualmente "vazio") sobre a virtude.

O resultado do meu inventário das "três vias para a crítica do capitalismo" se apresenta então do seguinte modo: de um lado, todas as três se mostram, em certo sentido, produtivas e, de outro lado, se mostram deficitárias, de modos distintos. Em tal situação, há mais alternativas. Em princípio, nada atesta contra uma crítica "de vários frontes" a uma formação social existente. Poderíamos afirmar que as respectivas dimensões da problemática da ordem econômica e social capitalista, esboçadas aqui por meio das três vias de crítica, por vezes se sobrepõem (mesmo que não sempre) e que os aspectos criticados as vezes se iluminam reciprocamente (mesmo que não sempre). Talvez não haja então o problema específico do capitalismo (válido apenas para ele), no qual sua crítica tenha de se fixar, e também não haja, para sua crítica, um critério universalmente válido e inquestionável em qualquer período (de qualquer modo, não há um único critério válido para uma crítica que diz respeito a todas as dimensões da "vida no capitalismo"). Especialmente no tocante à dimensão ética, é possível que, em alguns casos, baste checar a plausibilidade do pano de fundo das auto-compreensões culturais vigentes.

Ainda que de modo breve e partindo de seus déficits, eu gostaria pelo menos de considerar algumas reflexões sobre o tipo ético de crítica, que podem levar a um resultado mais robusto (ou menos modesto).

A suposição a seguir afirma, então: as dimensões da crítica do capitalismo esboçadas acima não têm apenas pontos fortes e fracos, que decorrem de seus diferentes domínios de aplicação. Apenas quando tomadas conjuntamente elas estão em posição de gerar critérios para uma crítica do sistema social e econômico capitalista. Ou, dito de outro modo: esses pontos fracos se resolvem quando as três "dimensões" da crítica - não mais as "vias"! - forem observadas conjuntamente. Uma crítica do capitalismo como forma de vida (esta é minha sugestão para o título geral dessa abordagem) seria então uma crítica que relacionasse todas as três dimensões - o déficit funcional, o moral e o ético - entre si. Note bem: a questão acerca de se tal crítica seria "radical", isto é, se visaria uma transformação ou 
abolição completa, ou se seria reformista, não foi abordada de início e depende de seus resultados.

\section{Prospecto: Crítica do capitalismo como forma de vida}

Como, no entanto, é possível criticar o capitalismo como forma de vida? Quanto a isso, eu gostaria (e posso) apenas de mencionar, para concluir, alguns apontamentos.

- Como já indicado, seria decisivo para essa crítica especificar as "insuficiências éticas" do capitalismo, isto é, analisar a qualidade e a dinâmica particular assumidas sob as condições da acumulação de capital capitalista como, por exemplo, a instrumentalização e a ganância do "querer sempre mais"; isso significa: analisar a ganância e a instrumentalização institucionalizadas que podem ser efetivas sob relações capitalistas.

- Além disso, vale a pena salientar os momentos da problemática ética já indicados que, no sentido de uma crítica imanente, podem ser identificados como autocontraditórios. Acrítica da alienação [Entfremdung] e da coisificação, por exemplo, ganham um caráter bem menos nostálgico se esses elementos são analisados como frustrações da própria promessa moderna de liberdade e autodeterminação.

- Com isso, a via crítica restitui o seu direito, que discuti no início: é a interdependência de distúrbios funcionais, no sentido de crises práticas e perturbações, e déficits normativos, que pode valer como indícios da irracionalidade e do caráter errôneo do capitalismo como forma de vida. Certamente, uma forma de vida como o capitalismo sempre malogra normativamente. Que não queiramos viver assim, não é simplesmente uma decisão axiológica ética vinda do céu (ou da tradição). Isso depende, de sua parte, de déficits funcionais, bem como das perturbações e crises práticas associadas a eles. É decisivo, então, compreender a interpenetração dos dois momentos corretamente.

- Para essa crítica, pode ser determinado um tipo de meta-critério, que escapa da contingência das posições éticas substantivas: uma forma de vida bem sucedida seria então aquela que se caracteriza por possibilitar e não por limitar processos coletivos de aprendizagem - processos de aprendizagem que podem ser provocados, em parte, por crises de tipo funcional. Se o capitalismo faz isso, é mais do que questionável.

Tradução de Nathalie Bressiani

Revisão da tradução de Rúrion Melo 
Rahel Jaeggi

\section{Referências}

ANGEHRN, E.; LOHMANN, G. (orgs). Ethik und Marx, Moralkritik und normative Grundlagen der Marxschen Theorie. Königstein/Ts: Hain bei Athenäum: 1986.

BELL, D. Die kulturellen Widersprüche des Kapitalismus. Frankfurt am Main: Campus Verlag, 1991.

BOLTANSKI, L; CHIAPELLO, E. Der neue Geist des Kapitalismus. Konstanz: UVK Universitätsverlag Konstanz, 2003.

MARX, K. “Das Kapital. Kritik der politischen Ökonomie. Erster Band. Der Produktionsprozess des Kapitals". In: MARX, K.; ENGELS, F. Werke (MEW). Berlin: Institut für Marxismus-Leninismus beim ZK der SED 1867, pp.1956ff .

SOMBART, W. Der moderne Kapitalismus. Historisch-systematische Darstellung des gesamteuropäischen Wirtschaftslebens von seinen Anfängen bis zur Gegenwart. Paderborn: Verlag Schöningh, 1902/2012.

TAYLOR, C. What's wrong with Capitalism? New Left Review, n.2 March/April 1960, pp.5-11.

VAN PARIJS, P. What (if anything) is intrinsically wrong with Capitalism? Philosophica 34, 1984 (2), pp.85-102.

WILDT, A. “Gerechtigkeit in Marx' ,Kapital'”. In: ANGEHRN, E.; LOHMANN, G. (Hrsg.). Ethik und Marx, Moralkritik und normative Grundlagen der Marxschen Theorie. Königstein/Ts.: Hain bei Athenäum, 1986, pp.149-173.

WOOD, A. W. Karl Marx. London: Routledge, 1981.

Recebido em: 01.12.2015 Aceito em: 20.12.2015 